\title{
Research on Urea-related Deposit in the Exhaust Pipe of SCR System
}

\author{
Zhu Neng ${ }^{1,2}, L v \operatorname{Lin}^{1}$, and Chen $\mathrm{Shi}^{2}$ \\ ${ }^{1}$ Key Laboratory of High Performance Ship of Ministry of Education, Wuhan University of Technology, Wuhan, China \\ ${ }^{2}$ Rules \& Technology Centre, China Classification Society, Shanghai, China
}

\begin{abstract}
At present, numbers of commercial vehicles equipped with SCR system have been observed to generate deposit on exhaust pipe wall after operation for a certain time. Deposits can be hardly dissolved in water and decomposed by heating. Once formed up, deposits are so hard to be cleaned that bringing significant influence on the SCR system and engine. In this paper, deposits in exhaust pipes for automotive diesel engines were studied by thermo-gravimetric (TG) analysis method. According to the TG results, we can see that inhibition of the polymerization reaction of HNCO to generate high polymer is the basic way to avoid deposits. Finally, we solve the deposit problem by leading the injector forward $2600 \mathrm{~mm}$ and wrapping the whole exhaust pipe with heat preservation material.
\end{abstract}

\section{Introduction}

Nowadays, selective catalytic reduction (SCR) which uses urea water solution (UWS) as the reductant is widely regarded as one of the most promising technology to reduce $\mathrm{NO}_{\mathrm{x}}$ emissions of diesel engine and to meet increasingly stringent emission regulation standards [1-4]. UWS streaming into the exhaust pipe is gradually heated by high-temperature exhaust. If reaching a certain temperature, the liquid begins to evaporate. Evaporated gas mainly consists of vapor, because the boiling point of water is lower than that of urea. However, there are many problems derived from the urea decomposition process. One of them is that deposit formation on catalyst and inlet pipe surfaces block the pores and the active sites of catalyst which decreases the durability of the SCR systems.

In the ideal situation, UWS generates reductant NH3 after evaporation, pyrolysis and hydrolysis [5-7]. Deposits are side products of urea via a series of chemical reactions.

In order to explore generation reasons and influence factors of deposits, Lifeng $\mathrm{Xu}$ [8] researched the influence of exhaust temperature and catalyst types (iron zeolite and copper zeolite) on deposits production, the results of which show that the lower the exhaust temperature is, the more easily the deposits form. Iron zeolite forms deposits more easily than copper zeolite. Research of Guanyu Zheng [9] indicates pipe wall temperature exerts certain influence on the formation of deposits. Other researches [10-14] showed that we could get hydrogen by urea pyrolysis reaction, which was considered as a potential source of hydrogen/fuel cell power. In addition, Stradella [15], Carp [16] and Lundstrom [17] also have carried on the related researches on urea pyrolysis. So a better understanding of urea decomposition process can lead to improvement in the SCR performance and overcome the shortcoming.

Therefore, in this study, thermal decomposition process of urea has been investigated utilizing thermo-gravimetric (TG) analysis method, in parallel with detecting the evolved gases by mass spectrometry (MS).

\section{Materials and methods}

\subsection{Source of the deposits}

A commercial vehicle is employed to conduct the research. Technical parameters of the engine and the test vehicle are shown in Table 1 . We have conducted a road durability test and verified the deposits inside of the exhaust pipe wall. The traveling distance is about 2000 $\mathrm{km}$, including suburban road, plain expressway and mountain road. The statistical results of engine operating conditions are shown in Figure 1, which indicated that the test covered a wide range of engine operating conditions and the exhaust flow field was complex and changeable. As shown in Figure 2, we find there are a large number of deposits on exhaust pipe wall after the vehicle traveling for $2000 \mathrm{~km}$.

\subsection{Test apparatus}

Based on the chemical and physical properties of deposits, its components were researched by spectrum and thermal analysis. Chemical analysis instruments are shown in Table 2. 
Table 1. Technical parameters.

\begin{tabular}{|c|c|c|}
\hline \multicolumn{2}{|c|}{ Parameter name } & Parameter value \\
\hline \multirow{7}{*}{ Vehicle } & $\begin{array}{c}\text { The maximum allowable } \\
\text { total mass }\end{array}$ & $31000 \mathrm{~kg}$ \\
\cline { 2 - 3 } & Unladen mass & $10200 \mathrm{~kg}$ \\
\hline \multirow{7}{*}{ Engine } & Displacement & $11.12 \mathrm{~L}$ \\
\cline { 2 - 3 } & Quantity of cylinders & 6 \\
\cline { 2 - 3 } & Air admission mode & $\begin{array}{c}\text { Supercharged } \\
\text { Inter-cooling }\end{array}$ \\
\cline { 2 - 3 } & Fuel system & $\begin{array}{c}\text { High pressure } \\
\text { common rail }\end{array}$ \\
\cline { 2 - 3 } & Rated rotate speed & $1900 \mathrm{r} /$ min \\
\cline { 2 - 3 } & Rated power & $257 \mathrm{~kW}$ \\
\cline { 2 - 3 } & & \\
\cline { 2 - 3 } & &
\end{tabular}

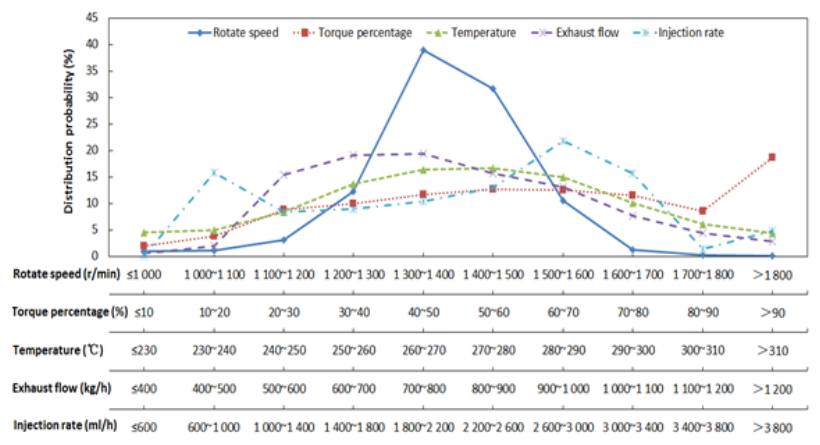

Fig. 1. Statistical results of engine operating conditions.

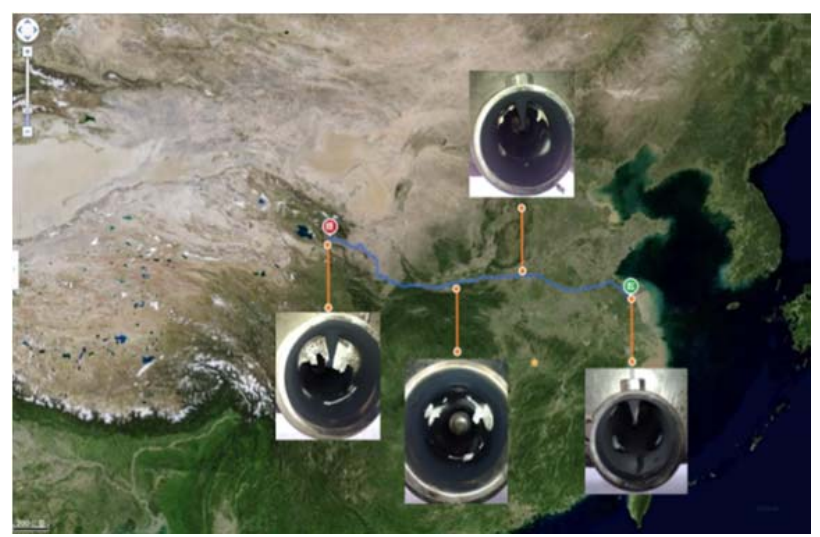

Fig. 2. The deposits of validation test.
Table 2. Test apparatus.

\begin{tabular}{|c|c|c|}
\hline Apparatus name & Specifications & Manufacturer \\
\hline D8 X-ray diffraction & D8 Adwance & Brooker \\
\hline TG-MS & STA449F3 & NETZSCH \\
\hline
\end{tabular}

\section{Results and discussion}

\subsection{X-ray diffraction analysis}

Every kind of crystalline substance has its special crystal structure. Crystalline substance in samples will be excited and produce secondary fluorescence X-ray with the irradiation of sufficient energy X-ray. Qualitative analysis of compound can be carried out by measuring the diffraction angles (peaks).In this paper, the deposits, biuret, and cyanuric acid were tested by D8 Adwance X-ray diffraction analyzer. The results are shown in Figure 3.

Contrasting the X-ray diffraction pattern of deposits and biuret, the result shows that the deposits are similar to biuret at the peak positions of $26.3^{\circ}$ and $28.1^{\circ}$. It's inferred that biuret is contained in the deposits. In addition, the deposits and cyanuric acid both have peak position at $19.8^{\circ}$ and $22.5^{\circ}$, and strong peak position at $29.8^{\circ}$, which further confirms that the cyanuric acid is contained in the deposits. The similar peak positions were observed in Lifeng Xu's [8] research on X-ray diffraction analysis of deposit.
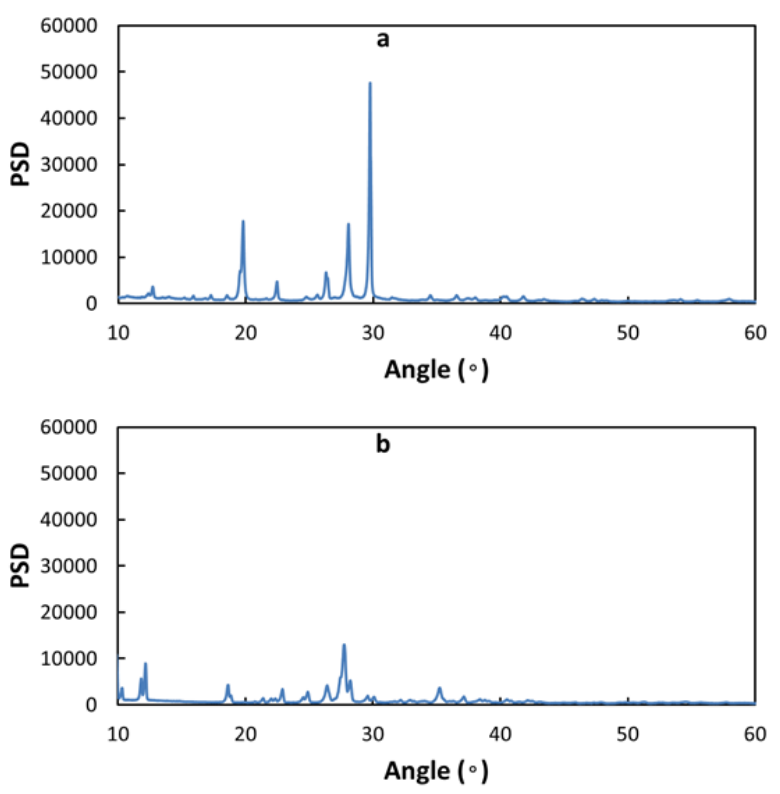


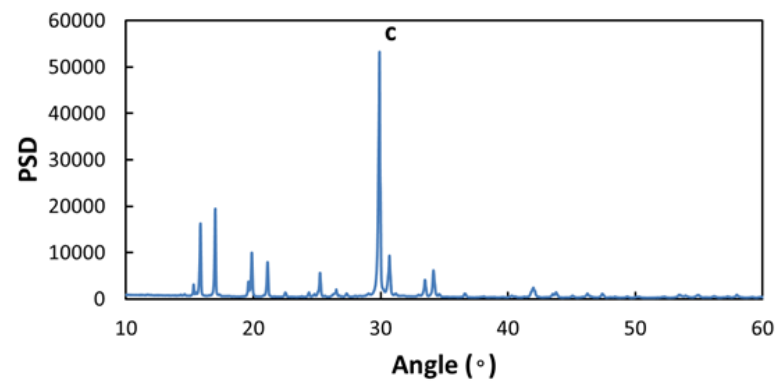

Fig. 3. X-ray diffraction spectrum of Deposits (a), Biuret (b) and Cyanuric acid (c).

\subsection{TG-MS analysis}

Thermal gravimetric - mass spectrometry (TG-MS) technology can obtain thermogravimetric curve of the samples by heating samples in thermal gravimetric analyzer, at the same time the evolved gas from thermal decomposition of the samples can be identified by transmitting to the mass spectrum analyzer. In this paper, deposits were analyzed by TG-MS instrument, the heating rate is $10{ }^{\circ} \mathrm{C} / \mathrm{min}$ and the purge gas is argon. The results are shown in Figure 4.

The deposits began to decompose slowly at $170^{\circ} \mathrm{C}$, at the same time $\mathrm{NH}_{3}$ and $\mathrm{HCNO}$ were observed, which indicated that the urea in the samples was decomposed (1), and the biuret was also decomposed (2).The mass loss was $8.4 \%$ until $250^{\circ} \mathrm{C}$.

$$
\begin{aligned}
\left(\mathrm{H}_{2} \mathrm{~N}\right)_{2} \mathrm{CO} & \rightarrow \mathrm{NH}_{3}+\mathrm{HNCO} \\
\left(\mathrm{H}_{2} \mathrm{NCO}\right)_{2} \mathrm{NH} & \rightarrow\left(\mathrm{H}_{2} \mathrm{~N}\right)_{2} \mathrm{CO}+\mathrm{HNCO}
\end{aligned}
$$

When the temperature was $250 \sim 315^{\circ} \mathrm{C}$, the thermogravimetric curve in this range was relatively flat. Only about $2.3 \%$ mass loss occurred and a small amount of $\mathrm{NH}_{3}$ and $\mathrm{HNCO}$ were observed. When the temperature was above $315{ }^{\circ} \mathrm{C}$, the residual mass decreased quickly, but the evolved gas $\mathrm{NH}_{3}$ remained at a very low value. This indicated that there were no more urea and biuret in the residue at this phase. However, we could observe that at around $400^{\circ} \mathrm{C}$ there was an escape peak of HNCO, which was mainly due to the decomposition of the cyanuric acid (3). At the same time, $\mathrm{CO}_{2}$ occurred due to the hydrolysis reaction of $\mathrm{HNCO}$ (4). Until $450^{\circ} \mathrm{C}$, decomposition of the deposits became slow and the residual mass was about $4.7 \%$.

$$
\begin{aligned}
(\mathrm{HNCO})_{3} & \rightarrow 3 \mathrm{HNCO} \\
\mathrm{HNCO}+\mathrm{H}_{2} \mathrm{O} & \rightarrow \mathrm{NH}_{3}+\mathrm{CO}_{2}
\end{aligned}
$$

When the temperature was during $600 \sim 720^{\circ} \mathrm{C}$, there was about $2.9 \%$ mass loss. This temperature was consistent with the decomposition temperature of ammeline, therefore the reaction (5) and (6) might occur.

$$
\begin{aligned}
& (\mathrm{HNCO})_{3}+\mathrm{NH}_{3} \rightarrow \text { ammelide }+\mathrm{H}_{2} \mathrm{O} \\
& \text { ammelide }+\mathrm{NH}_{3} \rightarrow \text { ammeline }+\mathrm{H}_{2} \mathrm{O}
\end{aligned}
$$

The deposits in diesel engine exhaust pipe were mostly cyanuric acid, which began to decompose when the temperature was above $250^{\circ} \mathrm{C}$. Along with the rise of the temperature, the decomposition rate speed up. Schaber's [18] research showed that in the process of urea pyrolysis, HNCO would react with biuret (7) or itself (8) to polymerize and create cyanuric acid. Therefore, inhibiting polymerization reaction of $\mathrm{HNCO}$ to generate high-molecular polymer by raising the lowest temperature of urea injection and exhaust temperature, we could avoid the formation of deposits.

$$
\begin{gathered}
\left(\mathrm{H}_{2} \mathrm{NCO}\right)_{2} \mathrm{NH}+\mathrm{HNCO} \rightarrow \mathrm{CYA}+\mathrm{NH}_{3} \\
3 \mathrm{HNCO} \rightarrow \mathrm{CYA}
\end{gathered}
$$

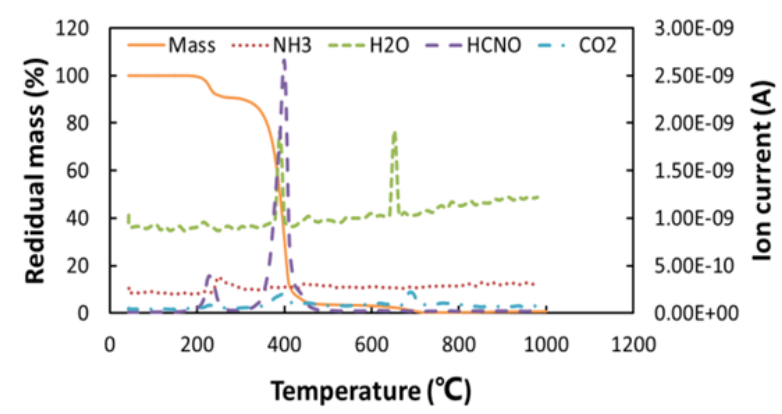

Fig. 4. TG - MS curves of the deposits.

\subsection{Final solution}

Urea pyrolysis process has close relationship with the temperature. As shown in Figure 5, the urea injector is $4100 \mathrm{~mm}$ downstream from the turbine. The heat dissipation between the exhaust pipe and environment inevitably lead to a lower exhaust temperature at the position of the injector.

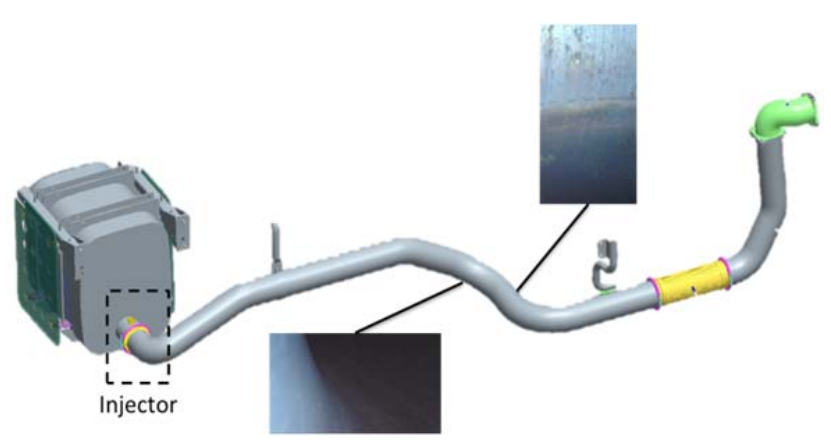

Fig. 5. Exhaust pipes assembly..

Refer to my previous research [19], we move the injector forward, hoping that it can avoid forming deposits on exhaust pipe wall by increasing the exhaust temperature at the position of injector. According to the arrangement of exhaust pipes, we lead the injector forward $2600 \mathrm{~mm}$ to downstream of the metal hose. In order to improve the wall temperature, heat preservation material is used to wrap the whole exhaust pipe. As 
shown in Figure 5, we can see that there are no deposits on the exhaust pipe wall.

\section{Conclusions}

This paper has a research on urea-related deposit in the exhaust pipe of SCR system. From the results shown above, the following items can be concluded:

(1) The results of X-ray diffraction analysis indicated that biuret and cyanuric acid are contained in the deposits.

(2) Inhibition of the polymerization reaction of HNCO to generate high polymer is the basic way to avoid deposits.

(3) According to improve the exhaust temperature and pipe wall temperature of the injector position, there are no deposits on the exhaust pipe wall.

\section{Acknowledgment}

The authors thank the support and grants by the National Natural Science Foundation of China (No. 51679176). We also appreciate the support of Key Laboratory of High Performance Ship Technology of Ministry of Education (Wuhan University of Technology) and China Classification Society (CCS).

\section{References}

1. T. Feng, "Developing and Simulation Research of Urea-SCR System Chemical Model of Diesel Engine," Wuhan: Wuhan University of Technology, (2013)

2. H. Wang, "Design and Optimization of Urea-SCR System Reductant Supply Compensation Strategy for Diesel Engines," Wuhan: Wuhan University of Technology, (2013)

3. T. Johnson, "Vehicular Emissions in Review," SAE Paper, 130105, (2013)

4. M. Koebel, M. Elsener, et al., "Urea-SCR a promising technique to reduce NOX emissions from automotive diesel engines," Catalysis Today, 59: 335 345, (2000)

5. C.S. Sluder, J.M.E. Storey, et al., "Low Temperature Urea Decomposition and SCR Performance," SAE paper, 1858, (2005)

6. G. Piazzesi, M. Elsener, O. Krocher, "Influence of $\mathrm{NO} 2$ on the hydrolysis of isocyanic acid over TiO2," Applied Catalysis B: Environmental, 65: 169 174, (2006)
7. N.W. Cant, D.C. Chambers, et al., "Formation and reactions of isocyanic acid during the catalytic reduction of nitrogen oxides," Topics in Catalysis, 10: 13 20, (2000)

8. L. Xu, W. Watkins, R. Snow, et al., "Laboratory and Engine Study of Urea-Related Deposits in Diesel Urea-SCR After-Treatment Systems," SAE Technical Paper, 1582, (2007)

9. G. Zheng, A. Fila, A. Kotrba, et al., "Investigation of Urea Deposits in Urea SCR Systems for Medium and Heavy Duty Trucks," SAE Technical Paper, 1941, (2010)

10. B.K. Boggs, R.L. King, G.G. Botte, et al., "Urea electrolysis: direct hydrogen production from urine," Chem. Commun, 32: 4859-4861, (2009)

11. R. Lan, S. Tao, T.S. Irvine, "A direct urea fuel cellpower from fertiliser and waste," Energy Environ. Sci., 3: 438-441, (2010)

12. A.N. Rollinson, G.L. Rickett, V.A. Lea-Langton, et al., "Hydrogen from urea-water and ammoniawater solutions," Appl. Catal. B, 106: 304-315, (2011)

13. A.N. Rollinson, J. Jones, V. Dupont, et al., "Urea as a hydrogen carrier: a perspective on its potential for safe, sustainable and long-term energy supply," Energy Environ. Sci., 4: 1216-1244, (2011)

14. J.M. Jonesa, A.N. Rollinson, "Thermogravimetric evolved gas analysis of urea and urea solutions with nickel alumina catalyst," Thermochimica Acta, 565: 39-45, (2013)

15. L. Stradella, M. Argentero, "A study of the thermal decomposition of urea, of related compounds and thiourea using DSC and TG-EGA," Thermochim Acta, 219: 315-323, (1993)

16. O. Carp, "Considerations on the thermal decomposition of urea," Rev. Roum. Chim., 46: 735-740, (2001)

17. A. Lundström, B. Andersson, L. Olsson, "Urea thermolysis studied under flow reactor conditions using DSC and FT-IR," Chem. Eng. J., 150: 544 550, (2009)

18. P.M. Schaber, J. Colson, S. Higgins, et al., "Thermal decomposition (pyrolysis) of urea in an open reaction vessel," Thermochimica Acta, 424: 131-142, (2004)

19. N. Zhu, L. Lv, C. Ye, "Investigation of Deposits in Urea-SCR System Based on Vehicle Road Test, " SAE Int. J. Engines, 10(2), 9275, (2017) 